Peer-Reviewed Article

ISSN: 2162-3104 Print/ ISSN: 2166-3750 Online

Volume 5, Issue 3 (2015), pp. 228-243

(C) Journal of International Students

http://jistudents.org/

\title{
Evidence that International Undergraduates Can Succeed Academically Despite Struggling with English
}

\author{
Barry Fass-Holmes, PhD \\ University of California, San Diego (USA) \\ Allison A. Vaughn, PhD \\ San Diego State University (USA)
}

\begin{abstract}
Many American universities require international applicants whose native language is not English to submit English proficiency exam scores presumably because of proficiency's potential to predict future academic success. The present study provides evidence, however, that such applicants can succeed academically despite struggling with English. Over 60\% of two cohorts of degree-seeking international freshmen at a West Coast public university struggled with English-they failed the university's English writing proficiency requirement. These international freshmen consequently were required to attend classes in English composition and/or English as a second language. Their average academic marks in these classes were between $D+$ and $C-(18-45 \%$ earned less than $C)$, yet their term grade point averages (which excluded the community college classes) were between $B$ and $B+$. The present findings indicate that these international undergraduates can succeed academically despite apparently inadequate English proficiency.
\end{abstract}

Keywords: academic success, English as a second language, grade point average, international undergraduates, TOEFL, writing

What level of English proficiency do international undergraduates whose native language is not English need in order to succeed academically at American universities? What metric(s) of English proficiency would be most accurate for American postsecondary admissions offices to use in predicting which international applicants are likely to succeed academically? These questions have become increasingly important in recent years as American public universities have admitted progressively larger numbers of nonimmigrant international applicants (Institute for International Education [IIE], 2013a). 
One of the reasons why American universities have admitted progressively larger numbers of international applicants is the financial benefit from non-residents' tuition/fees which are higher than residents' (England-Siegerdt, 2013; Hegarty, 2014). Higher tuition/fees have helped to offset the annual shortfalls in state government funding for higher education in America that began after the Great Recession of 2008 (Grapevine Project, 2014). State funding declined nationwide by 7.5\% in fiscal year (FY)2011-12 and by an additional 0.4\% in FY2012-13 (Kelderman, 2013). Consequently, annual total funding for American public universities declined by as much as $10.8 \%$ following the Great Recession (Grapevine Project, 2013). A rebound in state funding has been reported for FY2013-14 - a 5.7\% increase nationally (Rivard, 2014) — but it still is down from the level that preceded the onset of repeated post-recession cuts (Grapevine Project, 2014).

The financial benefits of admitting larger numbers of international applicants could be compromised by the expense of additional programs and services to meet these undergraduates' special needs. Their needs include compliance with immigration regulations and support in addressing academic difficulties, language and/or cultural barriers, personal issues, and discriminatory treatment (Hanassab \& Tidwell, 2002). Universities' admissions offices potentially could minimize expenses associated with programs and services for international undergraduates' special needs by implementing entrance requirements which maximize the likelihood that each admitted applicant will succeed academically.

One entrance requirement that many American universities have been using to predict international applicants' likelihood of academic success is the Test of English as a Foreign Language (TOEFL). Approximately 260 American universities require applicants to submit TOEFL scores (American Exam Services, 2013). These universities presumably require TOEFL scores for use as an indicator of international applicants' English proficiency that will predict future academic success (Andrade, 2006).

If English proficiency is necessary for international applicants who are not native English speakers to succeed academically at American universities (Andrade, 2006), then admitted applicants who subsequently struggle with English (despite having acceptable TOEFL scores) might be expected to struggle academically, also. This hypothesis is tested in the present study. Specifically, this study's primary goal was to evaluate the degree to which international first-time undergraduates struggle with English writing and also struggle academically despite having an acceptable TOEFL score. A secondary goal was to evaluate the degree to which increasing the minimum acceptable TOEFL score (in order to maximize admitted applicants' English proficiency and consequently maximize their ability to succeed academically) would affect the number of international applicants offered admission.

\section{Literature Review}

Many American universities have experienced increased enrollment of international undergraduates according to IIE's recent annual Open Doors snapshot survey (IIE, 2013a). This survey's results showed that the total number of international students enrolled in fall 2013 (FA13) was higher than in fall 2012 (FA12) at 72\% (274) of participating American universities. Moreover, academic year (AY)2012-13 was the seventh consecutive year in which IIE's Open Doors report showed an increase in the total number of international students in American higher education. New internationals enrolling in 2013 increased 7.2\% from 2012, and this increase was largely attributable to Chinese undergraduates studying in America whose numbers were up 21\% (IIE, 2013b). 
An increase in the number of international undergraduates also has occurred at the West Coast public university (hereafter referred to as "University") which was the focus of the present study (IIE, 2013a,b). This University, located in a large city's suburbs with over 20,000 undergraduates and recognized nationally for academic and research excellence (U.S. News and World Report's top 10), is one of the Open Doors snapshot survey's 380 participants. Its snapshot survey data show that it experienced an increase in enrolled international undergraduates in FA13 compared to the previous fall (IIE, 2013a). The number of new first-time international undergraduates (excluding transfers) at this University was 784 in FA13 which represented a $20.4 \%$ increase from the corresponding number for FA12-651. The latter number, in turn, represented a $91.5 \%$ increase from the corresponding number for fall 2011 (FA11) — 340.

The University's increase in international undergraduates has been accompanied by a campuswide generalization that these students, as a whole, are struggling academically and are increasingly at risk for academic probation, disqualification, and/or dismissal from the university. An additional concern, especially among faculty members, is that these students collectively have deficient English writing skills which are inadequate to meet their academic requirements and challenges. One possible explanation for this generalization is that the increased number of international undergraduates attending the University has led to a proportional increase in the number of international students struggling academically rather than that academic struggles are a general characteristic of these undergraduates. This scenario could lead to an erroneous generalization that the University's international undergraduates collectively are struggling academically when, in fact, only a consistently small proportion is struggling from one year to the next. A recent study confirmed this explanation (Fass-Holmes \& Vaughn, 2014) — at most $10 \%$ of this university's international undergraduates admitted in fall 2009 (FA09), fall 2010 (FA10), or FA11 struggled in their university classes (as reflected by term grade point averages below 2.0 [C or "average"]) even though a majority of them struggled with English (they were required to attend classes in English composition and/or English as a second language, and up to $42 \%$ earned grades of $\mathrm{D}$ or $\mathrm{F}$ in those classes).

In the absence of relevant data about the allegedly struggling international undergraduates' numbers and characteristics, concerns arising from the above generalization could result in costly and/or ineffective admissions policy changes. One change under consideration at the University is an increase in the minimum acceptable TOEFL score (the University's current requirement is 83 or higher on the internet-based TOEFL). The underlying presumption behind increasing the TOEFL requirement is that international applicants with higher scores should be less likely to struggle with English and more likely to succeed academically (Andrade, 2006).

Previous research on TOEFL scores' predictive power produced inconsistent results, howeversome studies showed a positive correlation between TOEFL scores and international undergraduates' grade point average (GPA) at American universities while other studies showed no correlation (reviewed by Graham, 1987; Johnson, 1988; Stoynoff, 1997; Wongtriat, 2010). A more recent report on Chinese, Taiwanese, Kuwaiti, Saudi Arabian, and United Arab Emirates undergraduates at a large state university indicated that a passing TOEFL score was about the same in predicting academic success as a passing grade in an English as a second language (ESL) class (Chen \& Sun, 2006). Thus, even though TOEFL scores have been used by many American universities' admissions offices, these scores might have insufficient power to accurately predict international applicants' future academic success (Kokhan, 2013; Wait \& Gressel, 2009). An increase in the TOEFL requirement instead could have unintended negative consequences such as the rejection of applicants who would succeed academically at the University and/or a financial 
shortfall due to fewer nonresident undergraduates paying higher tuition/fees.

\section{Methods}

The present study's goals originated from the University's Admissions Office staff's request for an analysis of GPA and English proficiency data that would support decision-making for the application cycle in progress at the time this article was written. The decision under consideration was whether to increase the TOEFL score requirement in order to maximize the English proficiency of admitted applicants and consequently maximize their ability to succeed academically. Because of the potential negative impact of this decision on the size of the entering class and resulting funds generated by non-resident tuition/fees, the Admissions Office had a compelling need for this analysis.

The University's Admissions Office staff specifically requested data for the two most recent cohorts of international first-time freshmen (NFRS) and non-degree-seeking exchange (education abroad program reciprocity [EAPR]) undergraduates entering the University who had at least one academic year of data available (i.e., FA11 and FA12 cohorts). The FA11 and FA12 cohorts were the most recent ones for whom GPAs were available at the time this study was conducted, and the international undergraduates who entered in FA11 were the first for whom the University's Admissions Office had fully implemented recruitment procedures (attending virtual fairs, distributing recruitment materials electronically, collecting information from overseas high schools, and attending American college fairs that provided opportunities for direct contact with foreign high school officials) targeting international applicants. These recruitment procedures were intended to increase the yield of international applicants accepting the offer of admission, and were in response to the University's shortfall of state funding.

Demographic and academic achievement data plus test scores (see Table 1) specified by Admissions Office staff for the FA11 and FA12 cohorts of the University's incoming NFRS and EAPR undergraduates were extracted from the university's student information system. Other demographic data (e.g., country of origin, department, major, etc.) were excluded from the analyses because previous research (Fass-Holmes \& Vaughn, 2014) showed that they produced small (magnitude) effect sizes and did not warrant their use in decision-making about TOEFL score requirements. EAPR undergraduates were included in the extraction to serve as a comparison (not as a control) group. These students are exempt from the university's TOEFL requirement and attend the university for a maximum of only one year. Admissions Office staff wanted to know the extent to which EAPR undergraduates struggled academically after being admitted without TOEFL scores (again, as a comparison). Transfer students were excluded from the extractions because of the University's transfer admission guarantee for community college students that required them to earn $\mathrm{C}$ or better in an English composition (EC) class at their previous institution rather than providing TOEFL scores. Domestic students also were excluded because of their lack of relevance to this study's goals. The data extractions additionally excluded amnesty seekers, applicants for permanent residency, asylees, permanent residents, refugees, and undocumented individuals; this was done for consistency with federal regulations' definition of non-immigrant international students (United States Department of State, n.d.).

To extract demographic and academic data plus SAT (college admission exam) and TOEFL scores for the two cohorts of international NFRS and EAPR undergraduates from the University's student information system databases, structured query language (SQL) programs were written and executed. The SQL programs also extracted each international undergraduate's unique campus ID and first and 
last names to facilitate accurate organization (using IRB-approved procedures) of all data within records within data files. The extracted data files retained authentic 0.00 GPAs (e.g., all Fs in an academic term's classes) and excluded artifactual ones (e.g., all "Pass" in an academic term's classes). Descriptive statistical analyses were performed (using spreadsheet software) on the data files to determine the extent to which either cohort struggled academically or excelled academically. GPAs below 2.0 (C) are considered "struggling" at the University, while GPAs at or above 3.5 (between B+ and A-) are considered "excelling." Descriptive statistics also were computed to determine the percentage of each cohort's NFRS required to participate in the community college EC and ESL classes and the percentages of participants who struggled or excelled in these classes. Correlation analyses were performed (using Statistics Open For All software) to determine the magnitude of association between TOEFL scores, total SAT scores (for comparison purposes), or academic marks in the community college classes (predictor variables) and term GPAs (outcome variable). Logistic regression analyses were performed (using PSPP and StatView software) to determine the magnitude of association between TOEFL scores (predictor variable) and participation in the community college classes (binary outcome variable; yes vs. no); and between TOEFL scores (predictor variable) and academic standing (binary outcome variable; good vs. not good).

\section{Table 1}

\section{Categories of Demographic, Academic, and Test Data Extracted for the Two Cohorts}

Category
applicant type-NFRS or EAPR
country of citizenship
2011-12 term GPAs_-fall, winter, spring
$2012-13$ term GPAs_-fall, winter, spring
SAT total score—-student's highest sitting; NFRS only
TOEFL score-NFRS only
English writing requirement—passed or failed
community college EC class-participation; academic mark
community college ESL class-participation; academic mark
academic standing-good, probation, subject to disqualification, disqualified

Note. International applicants can substitute the SAT Reasoning Writing Section score, advanced placement English exam score, or two transferable college level English writing course marks (B or better) for the TOEFL score. In addition to this application requirement, admitted NFRS (including domestics) must pass an English writing exam. Students who fail the exam are required to attend an EC class and/or an ESL class taught on campus by a local community college's instructors. Academic marks in these classes are excluded from the University's official GPAs. Abbreviations: NFRS=international first-time degreeseeking freshmen; EAPR=exchange visitor undergraduates; GPAs=grade point averages; EC=English composition; ESL=English as a second language

\section{Results}

\section{Descriptive Analyses-Demographics}

The total number of international NFRS (including ones in visa categories other than degreeseeking; United States Department of State, n.d.) entering the University increased dramatically over the past three fall terms (see Figure 1). The FA12 international NFRS cohort ( $\mathrm{n}=651$ out of 4,573 total NFRS) was almost twice as large as its FA11 counterpart $(n=340)$. In comparison, the 
FA12 EAPR cohort ( $n=191)$ was almost $20 \%$ smaller than its FA11 counterpart $(n=210)$. China and South Korea were the home countries of the overwhelming majority of the FA11 and FA12 NFRS cohorts-60\% and 35\%, respectively, for FA11; 55\% and 33\%, respectively, for FA12.

\section{Descriptive Analyses-Test Scores}

Table 2 shows the mean TOEFL and total SAT scores, standard deviations, and number of NFRS test-takers for the two cohorts. The FA11 and FA12 cohorts had identical mean TOEFL scores and nearly identical total SAT scores, although the FA12 cohort had lower variability and about 1.5 times as many test-takers.

\begin{tabular}{|c|c|c|c|c|c|c|}
\hline & \multicolumn{3}{|c|}{ TOEFL } & \multicolumn{3}{|c|}{ SAT } \\
\hline & Mean & S.D. & $\mathrm{n}$ & Mean & S.D. & $\mathrm{n}$ \\
\hline $\begin{array}{l}\text { FA11 } \\
\text { NFRS }\end{array}$ & 99 & 37 & 277 & 1829 & 371 & 305 \\
\hline $\begin{array}{l}\text { FA12 } \\
\text { NFRS }\end{array}$ & 99 & 7 & 448 & 1872 & 308 & 570 \\
\hline
\end{tabular}

Note: FA11=fall 2011; FA12=fall 2012; NFRS=international first-time degree-seeking freshmen; TOEFL=Test Of English as a Foreign Language; S.D.=standard deviation; $\mathrm{n}=$ number of students
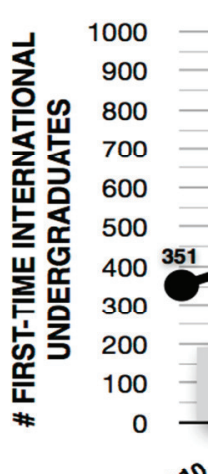
EA 10 \&PN

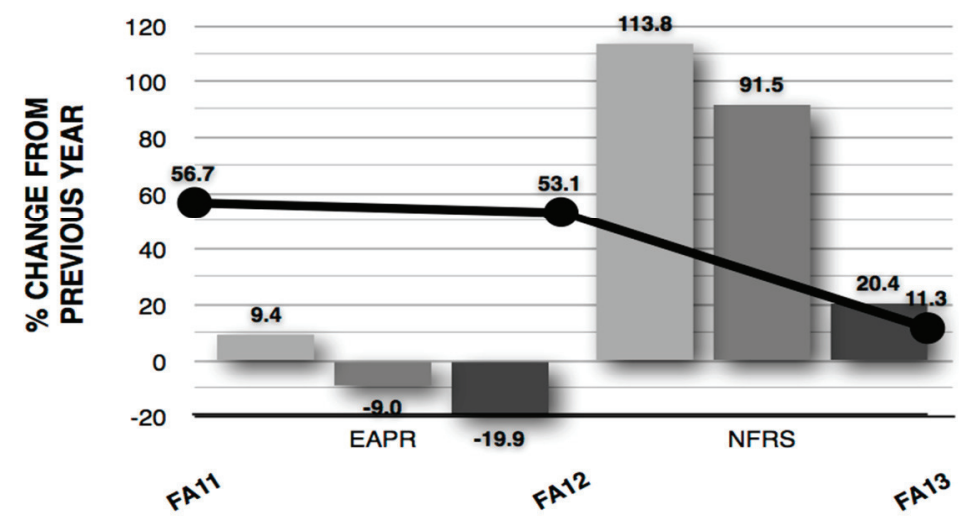

- total - FA10 FA11 EA12 FA13 - total - FA11 aA12 - FA13
Figure 1.

The number of international firsttime undergraduates entering the University increased dramatically over the past three fall terms as shown in the upper graph. Values above each data point in the line graph represent total counts for each cohort of international firsttime undergraduates; values above each bar represent exchange visitor (EAPR) or freshmen (NFRS) counts for each cohort. The rate of increase, as indicated by year-to-year percentage change, has trended downward as shown in the bottom graph. Values above each data point in the line graph and above or below each bar represent percentage change from the previous year.

Abbreviations: FA10=fall 2010; FA11=fall 2011, FA12=fall 2012, FA13=fall 2013 


\section{Descriptive Analyses-GPAs}

The FA11 and FA12 cohorts' international NFRS and EAPR earned term GPAs which averaged between 3.0 (B) and 3.6 (between $\mathrm{B}+$ and $\mathrm{A}-$-) in the academic years for which GPA data were available at the time of this study (see Figure 2). These mean GPAs' distribution was skewed to the right rather than normal-less than $10 \%$ of these undergraduates earned term GPAs below 2.0 (i.e., struggled academically) as shown in Figure 3, and more than 35\% earned 3.5 or higher (i.e., excelled academically) (data available from the authors upon request). The right skewness of these undergraduates' term GPAs is further evidenced by the frequency distributions in Figure 4.

\section{Descriptive Analyses-Academic Standing}

An overwhelming majority (90-95\%) of the FA11 and FA12 cohorts' international NFRS and EAPR undergraduates maintained good academic standing during their first year of enrollment. However, up to $10 \%$ of these undergraduates were not in good standing; they instead had been placed on probation, became subject to disqualification, or were disqualified (data available from the authors upon request). The percentage of the FA11 cohort not in good academic standing was about the same in FA11 (5.0\%) as in WI12 (4.8\%), but increased in SP12 (8.3\%). The FA12 cohort had a higher number of students not in good academic standing; 2-3 times more of these undergraduates than FA11 counterparts had been placed on probation, became subject to disqualification, or were disqualified in FA12. However, because the FA12 cohort included more students than the FA11, the former's percentages not in good academic standing was below $10 \%$.

\section{FA11 COHORT}

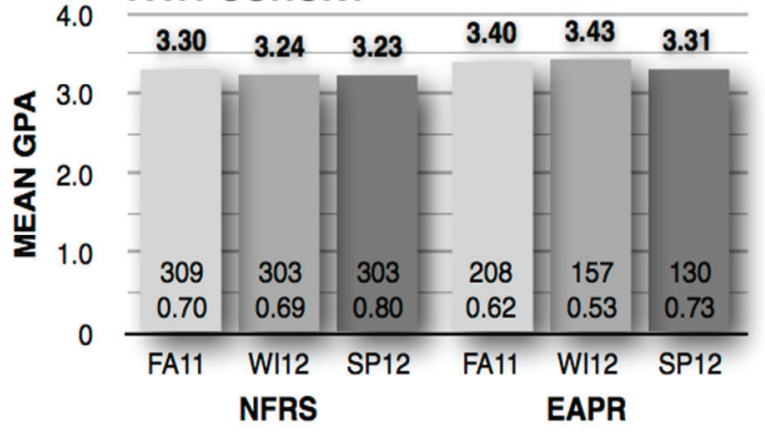

\section{FA12 COHORT}

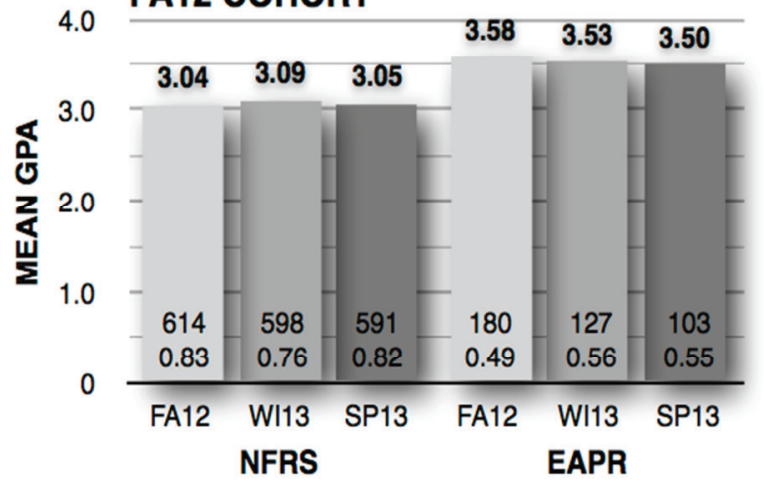

Figure 2.

International freshmen (NFRS) in the fall 2011 (FA11) cohort (top graphs) or in the fall 2012 (FA12) cohort (bottom graph) earned mean term grade point averages (GPAs) between 3.0 (B) and 3.3 $\left(\mathrm{B}^{+}\right)$. In comparison, the corresponding range for international exchange students (EAPR) was between 3.13 (B) and 3.6 (between $\mathrm{B}^{+}$and $\mathrm{A}^{-}$). The FA11 EAPR students did not have values for academic year 2012-13 because they attended the University for a maximum of one academic year. Values above each bar represent mean GPAs; values at the base of each bar represent counts and standard deviations.

Abbreviations: WI12=winter 2012, SP12=spring 2012, WI13=winter 2013, SP13=spring 2013 


\section{Descriptive Analyses_Participation and Performance in Community College English Classes}

Table 3 contains data on the two cohorts' participation in the community college English classes due to failing the University's English writing requirement. Sizable percentages of the FA11 and FA12 cohorts' international NFRS were required to participate in at least one of these classes during their first year of enrollment. Almost two-thirds of each cohort were required to participate in the fall term, about half in the winter term, and about a third in the spring term. More than twothirds of the participating students were Chinese, and between one-third and three-quarters of the Chinese undergraduates in the FA11 and FA12 cohorts participated in these classes.
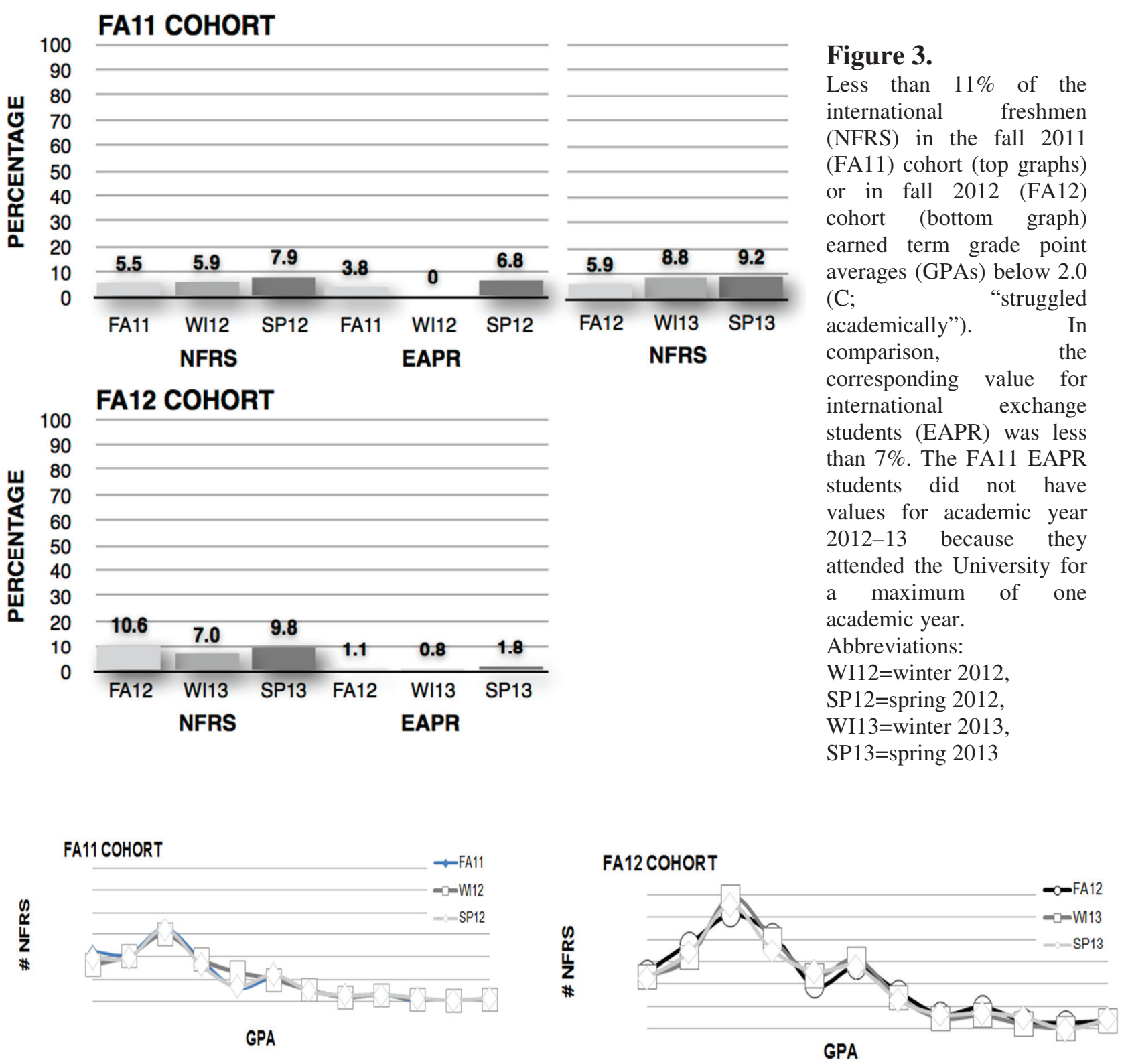

Figure 4.

Frequency distributions of the fall 2011 (FA11) and fall 2012 (FA12) cohorts' international freshmen's (NFRS) term grade point averages (GPAs) show a high degree of right skewness; more of these undergraduates earned 3.0 (B) or 3.3 (B+) GPAs than $2.0(\mathrm{C})$. 
Figure 5 shows the two cohorts' performance in the community college English classes. In general, the participants struggled in these classes - the FA11 participants' average EC mark was between D+ and C- and their average ESL mark was between C- and C; the FA12 participants' average EC mark was between $\mathrm{C}$ - and $\mathrm{C}+$ and their average ESL mark was between $\mathrm{C}$ - and $\mathrm{C}$. Between 40 and $45 \%$ of the FA11 participants earned below C in the EC class, while between 20 and $40 \%$ earned below $\mathrm{C}$ in the ESL class. The corresponding values for the FA12 participants were between 18 and $32 \%$ for the EC class, and between 27 and 37\% for the ESL class.

\section{FA11 COHORT}
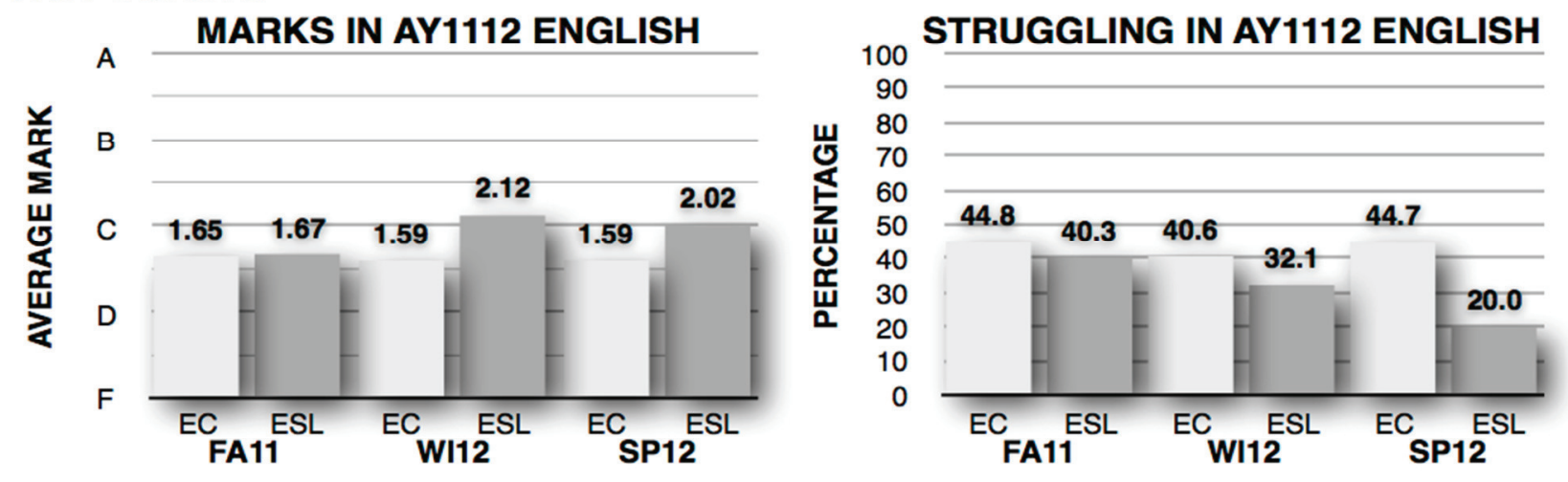

FA12 COHORT
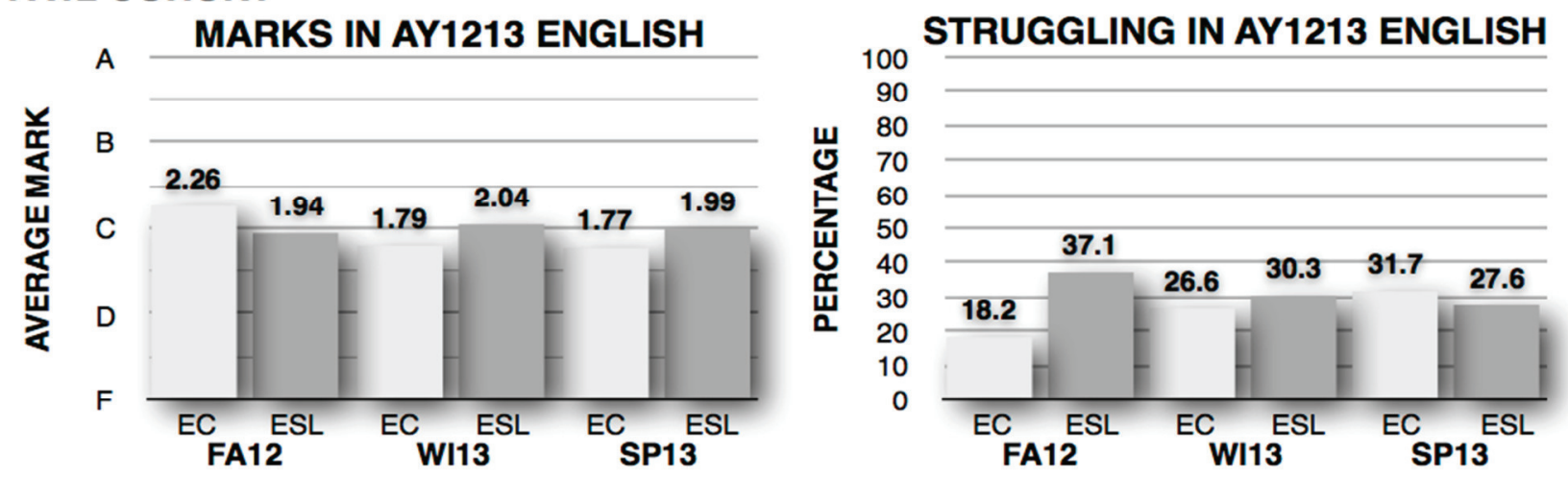

Figure 5.

The fall 2011 (FA11) cohort's participants earned an average mark between $\mathrm{D}^{+}(1.3)$ and $\mathrm{C}^{-}(1.7)$ in the community college English composition (EC) class, and between $\mathrm{C}^{-}$and $\mathrm{C}$ (2.0) in the English as a second language (ESL) class; $40-45 \%$ of the FA11 participants earned below C in EC, while 20-40\% earned below C in ESL (upper graphs). The fall 2012 (FA12) cohort's participants' average mark was between C- and C+ (2.3) in EC and between $\mathrm{C}^{-}$and $\mathrm{C}$ in ESL; $18-32 \%$ of the FA11 participants earned below $\mathrm{C}$ in EC, and $27-37 \%$ earned below C in ESL (lower graphs). Abbreviations: WI12=winter 2012, SP12=spring 2012, WI13=winter 2013, SP13=spring 2013

Figure 6 shows the community college English classes participants' performance in their University classes as reflected by their term GPAs (the University's official GPAs exclude marks earned in EC and ESL). Both cohorts' participants generally succeeded in their University classes - the FA11 and FA12 participants earned mean GPAs between B and $\mathrm{B}^{+}$. The percentage who earned GPAs below 2.0 ("struggled academically") varied between cohorts, terms, and English classes, ranging from 2.8 to $21.1 \%$. 


\section{FA11 COHORT}
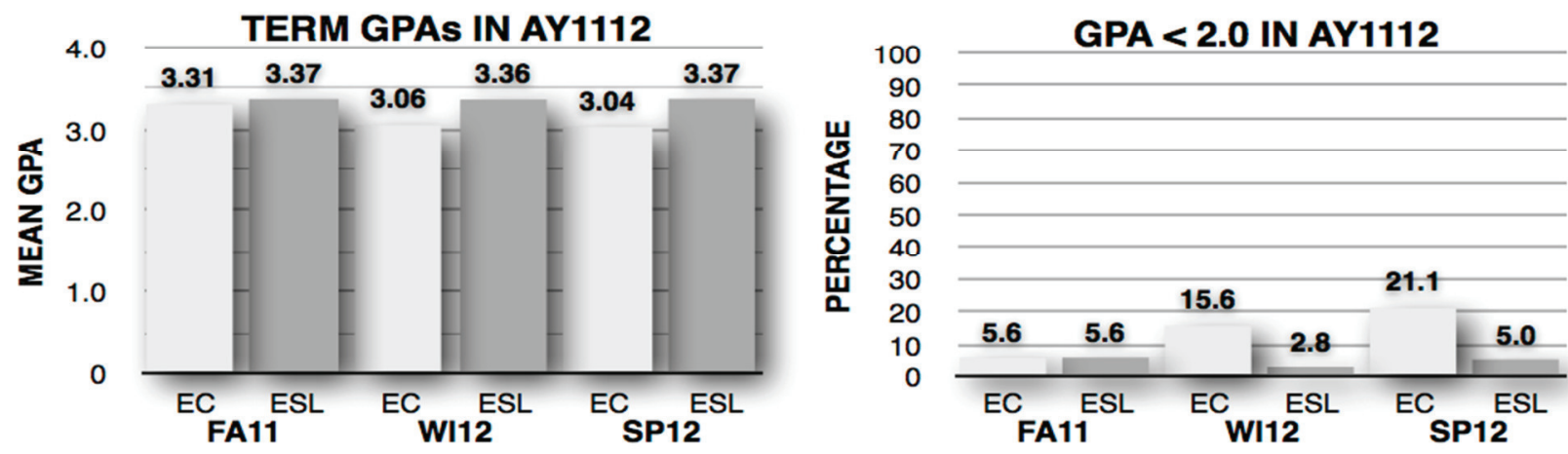

FA12 COHORT
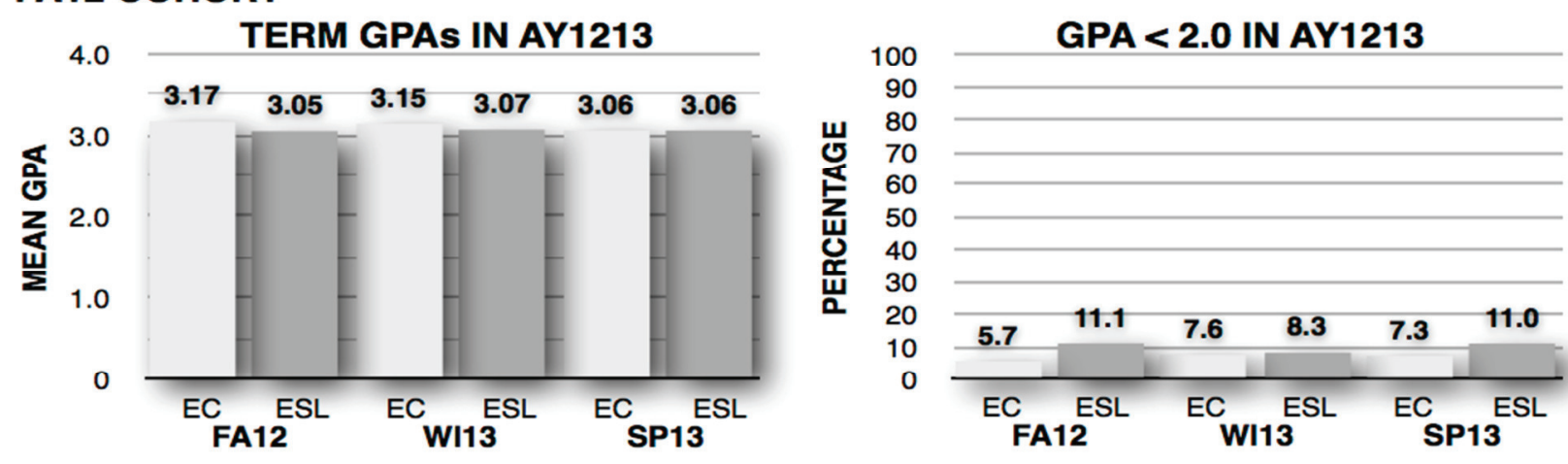

Figure 6.

The fall 2011 (FA11) cohort's participants in the community college English composition (EC) and English as a second language (ESL) classes earned mean term grade point averages (GPAs) between B (3.0) and B+ (3.3) in their University classes; 2-22\% of these students earned a term GPA below 2.0 ("struggled academically"). The fall 2012 (FA12) cohort's participants also earned average term GPAs between B and B+; 5-11\% of these students earned a term GPA below 2.0. Abbreviations: WI12=winter 2012, SP12=spring 2012, WI13=winter 2013, SP13=spring 2013

\section{Correlation Analyses}

To evaluate the degree to which English proficiency exam scores and/or participation and performance in the community college English classes predict academic success, we performed correlation analyses on the two cohorts of international NFRS' TOEFL scores, total SAT scores, or marks in the community college English classes (predictor variables) and term GPAs in the first year of enrollment (outcome variable). Significant positive correlation coefficients would indicate that the test score or English mark included in the analysis is a predictor of the term GPA included in the analysis - the higher the test score or English mark, the higher the term GPA; the lower the test score or English mark, the lower the term GPA.

Table 4 shows only the statistically significant results of these correlation analyses (non-significant results are available from the authors upon request). TOEFL scores were significant positive predictors only for the FA12 cohort's FA12 and WI13 GPAs. Total SAT scores were significant positive predictors only for the FA11 cohort's FA11 GPA and for the FA12 cohort's FA12, WI13, and SP13 GPAs. Community college ESL (but not EC) marks were significant positive predictors only for the FA11 cohort's WI12 and SP12 GPAs and for the FA12 cohort's FA12, WI13, and SP13 GPAs. Although these correlations ( $\mathrm{r}$ between 0.09 and 0.25 ) reached statistical significance, they were below the range of "small" (magnitude) effect sizes (Cohen, 1988). 
Table 3

Participation in Community College English Classes

\begin{tabular}{lllllll}
\hline & \multicolumn{4}{c}{ FA11 cohort } & \multicolumn{4}{c}{ FA12 cohort } \\
& FA & WI & SP & FA & WI & SP \\
\hline \# NFRS total & 310 & 303 & 303 & 614 & 603 & 593 \\
\# EAPR total & 210 & 157 & 133 & 190 & 132 & 109 \\
\# NFRS Chinese & 184 & 183 & 183 & 338 & 335 & 333 \\
\% NFRS Chinese & 59.4 & 60.4 & 60.4 & 55.0 & 55.6 & 56.2 \\
\# NFRS South Korean & 64 & 59 & 61 & 112 & 105 & 99 \\
\% NFRS South Korean & 20.6 & 19.5 & 20.1 & 18.2 & 17.4 & 16.7 \\
\# NFRS in community college English & 195 & 138 & 98 & 395 & 306 & 201 \\
\# EAPR in community college English & 2 & 3 & 0 & 0 & 1 & 2 \\
\% NFRS in community college English & 62.9 & 45.5 & 32.3 & 64.3 & 50.7 & 33.9 \\
\% NFRS \& EAPR in community college English & 37.9 & 30.7 & 22.5 & 49.1 & 41.8 & 29.1 \\
\# Chinese NFRS in community college English & 135 & 103 & 71 & 265 & 215 & 152 \\
\% Chinese NFRS in community college English & 73.4 & 56.3 & 38.8 & 78.4 & 64.2 & 45.6 \\
\% NFRS in community college English who were Chinese & 69.2 & 74.6 & 72.4 & 67.1 & 70.3 & 75.6 \\
\hline Note: NFRS=freshmen, EAPR=exchange students, FA11=fall 2011, FA12=fall 2012, FA=fall, & WI=winter, SP=spring
\end{tabular}

\section{Logistic Regression Analyses}

To evaluate the extent to which English proficiency exam scores predict English and academic struggles, we performed logistic regression analyses on the two cohorts' TOEFL scores (predictor variable) and participation in the community college classes (binary outcome variable; yes vs. no) and academic standing (binary outcome variable; good vs. not good; completion of 36 units during any three consecutive terms, term GPAs above 1.5, and cumulative GPA at or above 2.0 for two successive terms are required for good academic standing; probation, subject to disqualification, and academic disqualification are successive not good academic standings). Significant odds ratios are indicative that the TOEFL score is a predictor of participation in the community college classes and/or academic standing - the higher the TOEFL score, the higher the probability of not participating in the community college classes and/or having good academic standing; the lower the test score, the higher the probability of participating in the community college classes and/or having not good academic standing.

Table 5 shows the results of these logistic regression analyses. TOEFL scores were significant predictors for both cohorts' participation in the community college English classes but not for academic standing. These results are consistent with the descriptive statistics' results showing that between one- and two-thirds of each cohort's international NFRS participated in at least one community college English class (see Table 3), and that at most only 10\% were not in good academic standing.

Even though the logistic regression analyses indicate that the TOEFL score is a statistically significant predictor of English struggles, the results in Figure 7 mitigate TOEFL's potential usefulness in admissions decisions. For both cohorts, an increase of the University's TOEFL requirement from 83 to 105 would achieve a reduction in the percentage of NFRS participating in the community college English classes from about two-thirds to about one-half. However, the 
FA11 cohort's size would be reduced to fewer than 50 NFRS and the FA12's to less than 100. Increasing the requirement to 110 would eliminate almost the entire FA11 cohort and increasing it to 115 would eliminate almost the entire FA12 cohort.

Table 4

Statistically Significant Predictors of International Degree-Seeking First-Time Freshmen's Term GPAs

\begin{tabular}{llllll}
\hline Cohort & Predictor & Term & $r$ & $d f$ & $p$ \\
\hline \multirow{2}{*}{ FA11 } & ESL mark & WI12 & 0.25 & 70 & $<.05$ \\
& ESL mark & SP12 & 0.24 & 70 & $<.05$ \\
& total SAT & FA11 & 0.14 & 291 & $<.02$ \\
FA12 & ESL mark & FA12 & 0.22 & 302 & $<.001$ \\
& ESL mark & WI13 & 0.16 & 300 & $<.01$ \\
& ESL mark & SP13 & 0.11 & 301 & $<.05$ \\
& TOEFL & FA12 & 0.14 & 447 & $<.01$ \\
& TOEFL & WI13 & 0.10 & 444 & $<.05$ \\
& total SAT & FA12 & 0.10 & 556 & $<.02$ \\
& total SAT & WI13 & 0.12 & 553 & $<.01$ \\
& total SAT & SP13 & 0.09 & 553 & $<.05$ \\
\hline
\end{tabular}

Note: $\mathrm{r}=$ Pearson's correlation coefficient, $\mathrm{df}=$ degrees of freedom, $\mathrm{p}=$ probability (significance level), FA11=fall 2011, WI12=winter 2012, SP12=spring 2012, FA12=fall 2012, WI13=winter 2013, SP13=spring 2013
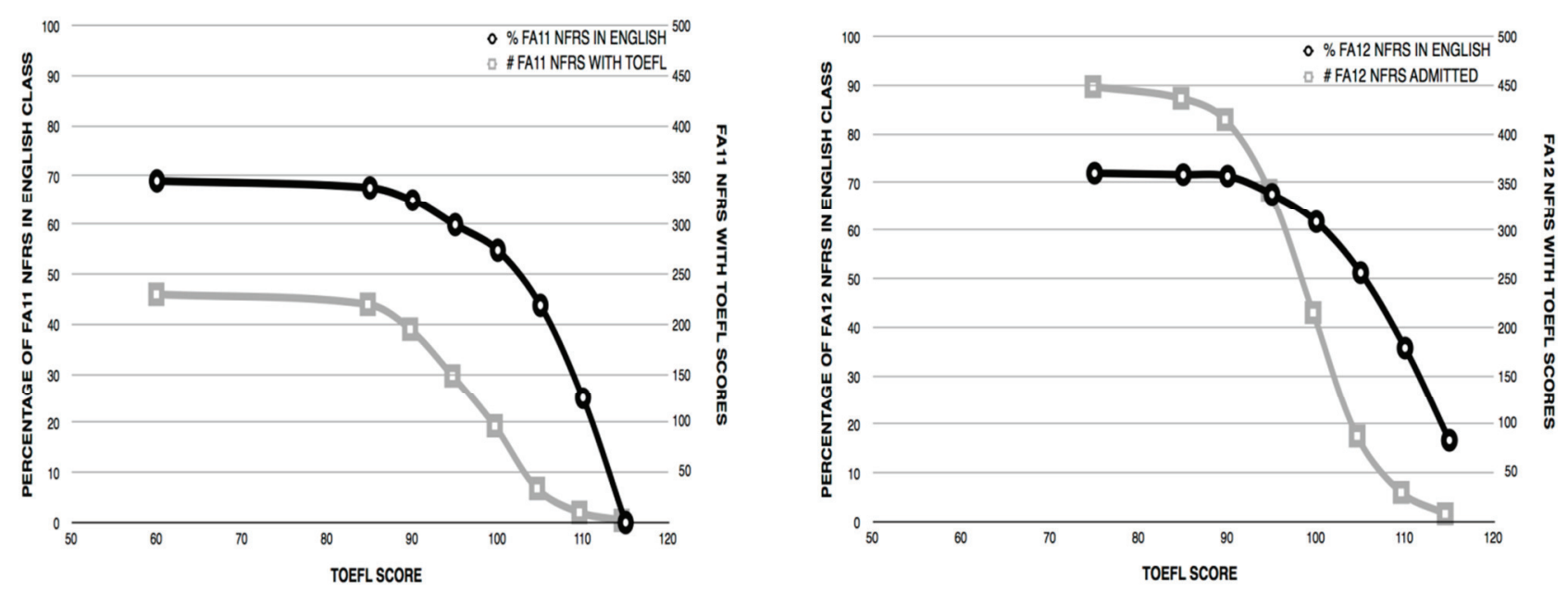

Figure 7.

The predicted effect, based upon the actual data, of increasing the University's TOEFL score requirement on the percentage of the fall 2011 (FA11) cohort's freshmen (NFRS) who would have participated in at least one of the community college English classes is shown by the curve with open circles (left y-axis), and the predicted effect on the cohort's size is shown by the line with open squares (right y-axis). An increase in the TOEFL requirement from 83 to 105 would be needed to achieve a reduction in English classes participation from about two-thirds to about one-half. 
Table 5 Logistic Regression Analyses of Community College English Class Participation and
Academic Standing

\begin{tabular}{|c|c|c|c|c|c|c|c|c|}
\hline Term & Predictor & Outcome & B & S.E. & Wald & Sig. & $\operatorname{Exp}(B)$ & $\mathrm{n}$ \\
\hline \multicolumn{9}{|c|}{ FA11 cohort } \\
\hline \multirow[t]{2}{*}{ FA11 } & TOEFL & English class & -0.12 & 0.02 & 22.4 & $<0.0001$ & 0.89 & 229 \\
\hline & & academic standing & -0.013 & 0.03 & 0.13 & n.s. & 0.99 & 229 \\
\hline \multirow[t]{2}{*}{ WI12 } & TOEFL & English class & -0.08 & 0.02 & 15.2 & $<0.0001$ & 0.92 & 229 \\
\hline & & academic standing & 0.04 & 0.04 & 1.11 & n.s. & 1.0 & 224 \\
\hline \multirow[t]{2}{*}{ SP12 } & TOEFL & English class & -0.09 & 0.02 & 19.1 & $<0.0001$ & 0.91 & 229 \\
\hline & & academic standing & 0.02 & 0.03 & 0.29 & n.s. & 1.0 & 224 \\
\hline \multicolumn{9}{|c|}{ FA12 cohort } \\
\hline \multirow[t]{2}{*}{ FA12 } & TOEFL & English class & -0.09 & 0.02 & 28.4 & $<0.0001$ & 0.91 & 449 \\
\hline & & academic standing & -0.013 & 0.02 & 0.26 & n.s. & 0.99 & 449 \\
\hline \multirow[t]{2}{*}{ WI13 } & TOEFL & English class & -0.11 & 0.02 & 42.5 & $<0.0001$ & 0.90 & 449 \\
\hline & & academic standing & -0.009 & 0.03 & 0.10 & n.s. & 1.0 & 447 \\
\hline \multirow[t]{2}{*}{ SP13 } & TOEFL & English class & -0.08 & 0.02 & 26.5 & $<0.0001$ & 0.92 & 449 \\
\hline & & academic standing & -0.016 & 0.02 & 0.46 & n.s. & 1.0 & 448 \\
\hline
\end{tabular}

Note: These analyses' outcome variables were dummy-coded; nonparticipation=0, English class participation=1; not good academic standing $=1$, good academic standing $=0$.

Abbreviations: FA11=fall 2011, WI12=winter 2012, SP12=spring 2012, FA12=fall 2012, WI13=winter 2013, SP13=spring 2013, B=logistic regression coefficient, S.E.=standard error, Wald=Wald statistic, Sig.=statistical significance level, n.s.=not significant, $\operatorname{Exp}(B)=$ odds ratio, $n=$ number of international degree-seeking first-time freshmen

\section{Discussion}

The present study tested the hypothesis that if English proficiency is necessary for international applicants who are not native English speakers to succeed academically at American universities (Andrade, 2006), then admitted applicants who subsequently struggle with English (despite having acceptable TOEFL scores) should struggle academically, also. The study's results showed instead that a sizable majority of the University's international NFRS who struggled with English succeeded academically. Therefore, these results disconfirm the hypothesis.

One of the study's goals in testing this hypothesis was to determine the extent to which two cohorts of international first-time undergraduates admitted to the University struggled with English (i.e., failed an English writing proficiency requirement; attended at least one community college English class) and also struggled academically (i.e., low GPAs; not good academic standing) despite meeting the University's TOEFL score requirement. A second goal was to evaluate the degree to which changing the TOEFL requirement (in order to maximize admitted applicants' 
English proficiency and consequently maximize their ability to succeed academically) would affect the number of international applicants offered admission.

Regarding the first goal, the present study's results demonstrate that the specific students in the two cohorts who struggled with English succeeded academically in general-they earned mean term GPAs between B (3.0) and B+ (3.3) in their University classes, and about $90 \%$ earned term GPAs at or above $\mathrm{C}(2.0)$. This percentage is considerably more than what would be expected if term GPAs were distributed normally (i.e., approximated a bell curve). Moreover, the overwhelming majority of these students maintained good academic standing; less than $10 \%$ were not in good academic standing. These students therefore succeeded academically despite struggling with English (cf., Andrade, 2006).

In addition, correlation analyses showed that the two cohorts' TOEFL score was a statistically significant predictor of academic struggles (term GPA) only for the FA12 cohort's FA12 and WI13 terms. These significant correlation coefficients were below the range of "small" (magnitude) effect sizes (Cohen, 1988), however. Logistic regression analyses additionally showed that the two cohorts' TOEFL score was a statistically significant predictor of their English struggles (participation in the English classes) but not their academic struggles (academic standing). The present study, like previous ones on TOEFL scores' predictive power (reviewed by Graham, 1987; Johnson, 1988; Stoynoff, 1997; Wongtriat, 2010), therefore indicates that the TOEFL score is inconsistent as a predictor of academic struggles.

Regarding the second goal, the present findings do not support campus advocacy for increasing the TOEFL score requirement. Predictions based upon the actual data showed that the TOEFL score requirement would have to be increased to a value (105-115) which also would drastically reduce the cohorts' sizes in order to achieve a meaningful reduction in English struggles. Reducing the number of admitted international NFRS would be counterproductive to the University's campus globalization efforts, and would compromise the financial benefit from these students' non-resident tuition/fees (Hegarty, 2014). The present findings instead support Wait \& Gressel's (2009) caveat that "TOEFL scores should not be used as a predictor of academic success in admissions screening” (p. 396) (see also Des Brisay, 1994; Kokhan, 2013).

The present findings additionally disconfirm anecdotal generalizations that the University's international undergraduates struggle academically. These anecdotal generalizations of widespread academic struggles cannot readily be attributed to a lack of assistance and/or support; the University historically has provided strong support to its non-native English speaking NFRS and EAPR through a wide range of programs and services to promote student satisfaction, engagement, and retention (e.g., orientations; academic and immigration advising; intramural sports; mentoring programs; one-on-one English tutoring; social and cultural events; student organizations; etc.). A more likely explanation is that the generalizations are due to annual increases in international undergraduates entering the University — as the number of enrolled international undergraduates increases, the number who struggle academically increases also (Fass-Holmes \& Vaughn, 2014). Importantly, however, the percentages of international undergraduates in the present study who struggled academically were relatively stable (about one tenth or less), and these percentages were less than what would be expected if GPAs were distributed normally. Two alternative explanations have not been supported by the results of our preliminary analyses designed to evaluate these alternatives: (a) the struggling undergraduates include immigrant students (applicants for permanent residency, amnesty-seekers, asylees, permanent residents, refugees, and/or undocumented students) rather than or in addition to non-immigrant (international) students; and (b) continuing, rather than new, international undergraduates are the ones who struggle 
academically.

How could international undergraduates, in general, have English weaknesses (as evidenced by their participation and performance in the community college classes) while simultaneously succeeding academically in their University classes (as evidenced by their GPAs)? One possible explanation is that the community college classes (EC; ESL) are more sensitive to English weaknesses than the University classes (e.g., Computer Science; Economics; Engineering; Mathematics). Another is that the community college instructors grade these students more strictly on English (grammar, spelling, etc.) while University instructors grade less strictly on English (instead focusing on whether the students show evidence of mastering class concepts). An additional possibility is that these students invest more time and energy on their University classes than on the community college classes. Each of these possibilities has been at least partially supported by the preliminary results of our survey questions designed to evaluate them.

In conclusion, the present findings suggest that international undergraduates at the University (and potentially ones at other postsecondary institutions also) can succeed academically despite struggling with English, and that changing the TOEFL score requirement for admissions purposes is not recommended. Policies and programs intended to support newly admitted international undergraduates would be most cost effective if they targeted the specific students with demonstrable academic struggles rather than all incoming international undergraduates who are not native English speakers.

\section{REFERENCES}

American Exam Services. (2013). TOEFL Scores-USA Universities Retrieved from http://www.americanexamservices.com/about-the-toefl/toefl-scores-usa-universities

Andrade, M.S. (2006). International students in English-speaking universities: Adjustment factors. Journal of Research in International Education, 5(2), 131-154.

Chen, Y., \& Sun, C. (2006). Language proficiency and academic performance. Proceedings of the 11th Conference of Pan-Pacific Association of Applied Linguistics, Korea, 11, 58-72.

Cohen, J. (1988). Statistical power analysis for the behavioral sciences (2nd ed.). Hillsdale, NJ: Erlbaum.

Des Brisay, M. (1994). Problems in developing an alternative to the TOEFL. TESL Canada Journal, 12(1), 47-57.

England-Siegerdt, C. (2013). Draft 2013 national tuition and fee report. Retrieved from http://www.wsac.wa.gov/sites/default/files/TuitionFeeReport-DRAFT.pdf.

Fass-Holmes, B., \& Vaughn, A. A. (2014). Are international undergraduates struggling academically? Journal of International Students, 4(1), 60-73.

Graham, J.G. (1987). English language proficiency and the prediction of academic success. TESOL Quarterly, 21(3), 505-521.

Grapevine Project (2013). One-year (FY12-FY13), two-year (FY11-FY13), and five-year (FY08-FY13) percent changes in state fiscal support for higher education, by state and by source of fiscal support. Retrieved from http://grapevine.illinoisstate.edu/tables/FY13/Table2_FY13.pdf

Grapevine Project (2014). One-year (FY13-FY14), two-year (FY12-FY14), and five-year (FY09-FY14) percent changes in state fiscal support for higher education. Retrieved from http://grapevine.illinoisstate.edu/tables/FY14/Table2_GPV14.pdf. 
Hanassab, S., \& Tidwell, R. (2002). International students in higher education: identification of needs and implications for policy and practice. Journal of Studies in International Education, 6(4), 305-322.

Hegarty, N. (2014). Where we are now-the presence and importance of international students to universities in the United States. Journal of International Students, 4(3), 223-235.

Institute for International Education. (2013a). Fall 2013 snapshot survey finds strong growth in international students. Retrieved from http://www.iie.org/Who-We-Are/News-andEvents/Press-Center/Press-Releases/2013/2013-11-11-Open-Doors-Fall-Snapshot-Survey.

Institute for International Education. (2013b). Open Doors 2013: Retrieved from http://iie.org/Who-We-Are/News-and-Events/Press-Center/Press-Releases/2013/2013-1111-Open-Doors-Data.

Johnson, P. (1988). English language proficiency and academic performance of undergraduate international students. TESOL Quarterly, 22(1), 164-168.

Kelderman, E. (2013). State spending on higher education rebounds in most states after years of decline. Chronicle of Higher Education. Retrieved from http://chronicle.com/article/State-Spending-on-Higher/136745/.

Kokhan, K. (2013). An argument against using standardized test scores for placement of international undergraduate students in English as a Second Language (ESL) courses. Language Testing, 30(4), 467-489

Rivard, R. (2014). State higher ed budgets rebound. Inside Higher Education. Retrieved from http://www.insidehighered.com/news/2014/01/20/state-higher-ed-funding-rebounds-notyet-where-it-was-recession.

Stoynoff, S. (1997). Factors associated with international students' academic achievement. Journal of Instructional Psychology, 24(1), 56-68.

United States Department of State. (n.d.). Student visas. Retrieved from http://travel.state.gov/visa/temp/types/types_1268.html

Wait, I.W., \& Gressel, J.W. (2009). Relationship between TOEFL score and academic success for international engineering students. J. of Engineering Education, 98(4), 389-398.

Wongtriat, R. (2010). English language proficiency and academic achievement of international students: A meta-analysis. (Doctoral dissertation). Retrieved from ProQuest Dissertations and Theses. (UMI Number 3417016)

\section{Author the Authors:}

BARRY FASS-HOLMES received his Ph.D. in Psychology from Clark University. He currently is the Analytical Studies Coordinator for the International Students \& Programs Office in the International Center at the University of California, San Diego. His research focuses on international students' academic achievement. We thank Lynn C. Anderson, Dulce Amor L. Dorado, Matthew Kearney, and Dr. Kirk Simmons for their helpful suggestions. His email address is bfholmes@ucsd.edu

ALLISON A. VAUGHN received her Ph.D. in Psychology from the University of Utah. She is an assistant professor in the Psychology Department at San Diego State University. Her research interests include social relationships, (friends, significant others, work colleagues), mental health (anxiety, depression), physical health (cardiovascular functioning; e.g., blood pressure and heart rate), and student achievement. Her email address is avaughn@mail.sdsu.edu. 